\title{
Optical and Structural Properties of Solvent Free Synthesized Starch/Chitosan-ZnO Nanocomposites
}

\author{
Anandhavelu Sanmugam, ${ }^{1,2}$ Dhanasekaran Vikraman, ${ }^{3}$ \\ Sethuraman Venkatesan, ${ }^{2}$ and Hui Joon Park ${ }^{4,5}$ \\ ${ }^{1}$ Department of Chemistry (SerH), Vel Tech Multi Tech, Chennai 600062, India \\ ${ }^{2}$ Department of Industrial Chemistry, School of Chemical Sciences, Alagappa University, Karaikudi, Tamilnadu 630003, India \\ ${ }^{3}$ Division of Electronics and Electrical Engineering, Dongguk University-Seoul, Seoul 04620, Republic of Korea \\ ${ }^{4}$ Division of Energy Systems Research, Ajou University, Suwon 16499, Republic of Korea \\ ${ }^{5}$ Department of Electrical and Computer Engineering, Ajou University, Suwon 16499, Republic of Korea
}

Correspondence should be addressed to Dhanasekaran Vikraman; v.j.dhanasekaran@gmail.com and Hui Joon Park; huijoon@ajou.ac.kr

Received 31 October 2016; Accepted 5 March 2017; Published 20 April 2017

Academic Editor: Giovanni Bongiovanni

Copyright (C) 2017 Anandhavelu Sanmugam et al. This is an open access article distributed under the Creative Commons Attribution License, which permits unrestricted use, distribution, and reproduction in any medium, provided the original work is properly cited.

\begin{abstract}
The objective of this work is to develop an environmentally friendly method for preparation of $\mathrm{ZnO}$ nanocomposites. $\mathrm{ZnO}$ nanocomposites were prepared by three natural fibers such as coir, sawdust, and chitosan using aqueous solution of zinc chloride and sodium hydroxide. The functional groups of $\mathrm{ZnO}, \mathrm{C}=\mathrm{O}$ for polysaccharide, and $\mathrm{N}-\mathrm{H}$ bending vibration of amine were confirmed by FTIR spectroscopy. A new high intensity absorption band has been observed at $424 \mathrm{~cm}^{-1}$ which corresponds to the $\mathrm{E}_{2}$ mode of hexagonal $\mathrm{ZnO}$. The crystallinity and phase formation of coir, chitosan, and sawdust combined $\mathrm{ZnO}$ nanocomposites were confirmed by X-ray diffraction patterns. XRD patterns revealed the polycrystalline nature of $\mathrm{ZnO}$ composites belonging to the hexagonal phase with (101) preferential lattice orientation. The microstructural parameters were calculated for coir, chitosan, and saw wood combined $\mathrm{ZnO}$ composites. Also texture coefficients were estimated for all the diffraction lines of $\mathrm{ZnO}$ based nanocomposites. SEM and TEM analyses confirmed evenly distributed nanosized grains in the $\mathrm{ZnO}$ composites. The UV-Vis absorption spectra were observed where the blue shift absorption peak was at $334 \mathrm{~nm}$. The optical band gap values were estimated in the range of 3.18-3.26 eV. The emission peak was observed at $\sim 388 \mathrm{~nm}$ and $\sim 463 \mathrm{~nm}$ by photoluminescence spectroscopy.
\end{abstract}

\section{Introduction}

The ecofriendly chemical route preparation is a modern research trend for global warming prevention. In this work is an initiative to concentrate the synthesis of metal oxides using biological waste. The various types of metal oxide nanoparticles, such as zinc oxide nanoparticles $(\mathrm{ZnO})$, have accomplished tremendous attention and have been widely utilized in a variety of applications including optical materials, cosmetics, functional devices, catalysts, and UV-absorbers. $\mathrm{ZnO}$ is a wide band gap $(3.37 \mathrm{eV})$ semiconductor, which has been extensively investigated for various applications such as transparent conductive coatings [1], electrodes for dyesensitized solar cells [2], and gas sensors [3]. The wide band gap makes $\mathrm{ZnO}$ a good candidate for blue optoelectronic applications and their large exciton energy makes it possible to employ excitonic recombination process as lasing mechanism. Synthesis of $\mathrm{ZnO}$ nanoparticles in aqueous solution has advantages like simplicity, low cost, lower reaction temperature, and soluble materials whose surface functionalization can be investigated. Recently, template-free solvothermal approach was employed for fabrication of large-scale olivelike $\mathrm{ZnO}$ nanoparticles which exhibit a very strong ultraviolet emission centered at $383 \mathrm{~nm}$ and a weak green luminescence emission at around $522 \mathrm{~nm}$ [4].

Natural fibers used as biocomposite fillers have received much interest in offering notable advantages over synthetic fibers [5], in addition to being of low cost, environmentally 
friendly, renewable, and biodegradable, as well as having a low density [5]. Coconut coir cut fiber is the remaining waste product when long fibers are extracted from coconut husk. It constitutes the short fibers and mesocarp pith of coconuts. Because coir dust has many characteristics, such as high water-holding capacity and slow decomposition, it has been extensively used as an environmentally friendly substitute for natural peat in potting media [6]. Sawdust is an inexpensive, widely available, and abundant natural material. It has been reported to exhibit ion exchange and complexion properties for the heavy metals. Sawdust has received particular attention as an economical adsorbent for removing zinc (II) ions from aqueous solutions due to its abundance, being easily available, and being of low cost. Furthermore, it will be a step ahead towards exploring the possibility on the use of waste biomass for industrial waste water pollution management. Chelating ability of chitosan with metals has been widely exploited for preparation of metal complexes [7] and metal composites [8]. Compared to other metal ions, chitosan has higher ability to form metal complexes with zinc metal [9].

Chitosan is actually containing heteropolymer of glucosamine and acetylglucosamine units. Hybrid materials based on chitosan along with oxide materials have been developed in recent years, due to excellent properties of individual compounds and outstanding synergistic effects simultaneously. Due to the biocompatibility, biodegradability, nontoxicity, and absorption properties of chitosan, chitosan protected nanoparticles can be easily integrated into systems relevant to pharmaceutical, biomedical, and biosensor applications [10]. Recently, Malini et al. [11] have successfully synthesized nanocomposite chitosan/ZnO membrane using chitosan membrane as well as green-synthesized nano- $\mathrm{ZnO}$ for antimicrobial properties. Currently, chitosan- $\mathrm{ZnO}$ complex attracted great importance for its potential use as an UV protector and antimicrobial activity [12]. $\mathrm{ZnO}$ nanostructures have considerable research interests due to their low cost, easy availability, and biocompatibility and possibility of performing surface modifications with different functional groups. Díez-Pascual and Díez-Vicente [13] reported the preparation of PHB-based bionanocomposites incorporating different contents of $\mathrm{ZnO}$ nanoparticles via a solution casting technique. They have demonstrated the dispersion of nanoparticles within the biopolymer without any surfactants or coupling agents. Azizi et al. [14] claimed dispersed cellulose nanocrystals/zinc oxide (CNCs/ZnO) nanocomposites as bifunctional nanosized fillers into poly(vinyl alcohol) (PVA) and chitosan (Cs) blend using a solvent casting method to prepare PVA/Cs/CNCs/ZnO bionanocomposites films.

This attempt was made to prepare $\mathrm{ZnO}$ using three different natural fibers like coir, sawdust, and chitosan using aqueous chemical bath comprising zinc chloride and sodium hydroxide as precipitant. The prepared samples are analysed using Fourier transform infrared spectroscopy (FTIR), Xray diffraction (XRD), UV-Vis spectroscopy, scanning electron microscopy (SEM), transmission electron microscopy (TEM), and photoluminescence spectroscopy (PL) techniques.

\section{Nanocomposites Preparation and Characterization Details}

The coir- $\mathrm{ZnO}$, sawdust- $\mathrm{ZnO}$, and chitosan- $\mathrm{ZnO}$ nanocomposites were prepared using chemical sol-gel route. The analytical grade chemical source was used in preparation process. The double distilled deionized water was used in the solution bath. The coconut coir fibers were collected from the waste of coir industry. The dust particles were removed and washed in double distilled deionized water 3 times and dried in the sunlight for 5 days. The fibers were again cut into small pieces, ground well in the mortar, and dried in the hot air oven at $60^{\circ} \mathrm{C}$ for $30 \mathrm{~min}$. Coir powder $(0.5 \mathrm{~g})$ was dispersed in the $50 \mathrm{ml}$ of water and heated up to $70^{\circ} \mathrm{C}$ for $30 \mathrm{~min}$ in the magnetic stirrer. Then, $50 \mathrm{ml}$ of $25 \% \mathrm{ZnCl}_{2}$ solution was added and heating continued at $70^{\circ} \mathrm{C}$ for $60 \mathrm{~min}$. The insoluble coir residue was filtered off using fine stainless steel mesh. $50 \mathrm{ml}$ of $25 \% \mathrm{NaOH}$ was added slowly at the rate of $5 \mathrm{ml} / \mathrm{min}$. The white color precipitate was formed and it could settle down within 24 hours. The prepared particles were washed 10 times using $500 \mathrm{ml}$ of deionized water and then filtered. Finally, the water was separated using suction pump and dried in an oven at $110^{\circ} \mathrm{C}$ for 2 hours and then sample was designated as coir- $\mathrm{ZnO}$.

Sawdust has been collected from sawmill without any other contamination or impurities. The particles dried in the direct sun light for 5 days and were sieved in the fine mesh, ground well in the mortar, and dried in the oven at $60^{\circ} \mathrm{C}$ for $30 \mathrm{~min}$. Sawdust powder was dispersed in the $50 \mathrm{ml}$ of water and heated up to $70^{\circ} \mathrm{C}$ for $30 \mathrm{~min}$ in the magnetic stirrer. Then, $50 \mathrm{ml}$ of $25 \% \mathrm{ZnCl}_{2}$ solution was added and heating continued at $70^{\circ} \mathrm{C}$ for $60 \mathrm{~min}$. The burette solution of $50 \mathrm{ml} 25 \% \mathrm{NaOH}$ was added slowly until white color was formed. This precipitate will be taken to settle down for 24 hours. The settled down precipitate was washed using $500 \mathrm{ml}$ of deionized water until the impurities were removed well. The collected precipitate was filtered using microfilter and it has been separated out using suction pump. The final product was dried in an oven at $110^{\circ} \mathrm{C}$ for 2 hours and then sample is designated as sawdust- $\mathrm{ZnO}$.

The chitosan- $\mathrm{ZnO}$ nanocomposites were prepared using the following experimental procedure. The commercially available chitosan was purchased for the synthesis process. It was extracted from crustacean exoskeletons, having an average molecular weight of $180 \mathrm{kDa}$ with $90 \%$ deacetylation. 0.5 grams of chitosan was dispersed in the $50 \mathrm{ml}$ of water with continuous stirring. The solution mixture was heated up to $70^{\circ} \mathrm{C}$ for 30 mins with the stirring. Thereafter $25 \% \mathrm{ZnCl}_{2}$ solution was mixed with chitosan solution bath and heating process continued for $60 \mathrm{mins}$. The insoluble chitosan has been removed using stainless steel mesh filtration process. $50 \mathrm{ml}$ of $25 \% \mathrm{NaOH}$ was added slowly using burette until the precipitate formation in the solution bath. This precipitate was took 24 hours to entirely settle down in the bottom of beaker. The prepared particles were washed several times using double distilled deionized water and then filtered. At the end of the process, the product was separated using suction pump and dried in an oven at $110^{\circ} \mathrm{C}$ for 2 hours. 
Fourier transform infrared spectra were recorded using Thermo-Nicolet-380 Madison, USA model. The structural studies were performed using an X-ray diffractometer (X'Pert PRO PanAlytical diffractometer) of $\mathrm{Cu} \mathrm{K}_{\alpha}$ radiation $(\lambda=$ $0.154 \mathrm{~nm}$ ). The morphological properties were analysed using scanning electron microscope with a model Hitachi-S3000 $\mathrm{H}$, Japan. The absorption spectra were taken using UVvisible spectrophotometer (2401 PC model; Shimadzu, Kyoto, Japan). The photoluminescence spectra were recorded on Perkin Elmer LS 55 Luminescence spectrometer with excitation at $325 \mathrm{~nm}$.

\section{Results and Discussions}

Fourier transform infrared spectroscopy (FTIR) analysis is used to identify the functional groups of prepared composites. FTIR spectra of coir- $\mathrm{ZnO}$, sawdust- $\mathrm{ZnO}$, and chitosan$\mathrm{ZnO}$ composites are presented in Figure $1(\mathrm{a}-\mathrm{c})$. From Figure 1 , the peaks are observed at 3437,3414 , and $3424 \mathrm{~cm}^{-1}$ corresponding to the $\mathrm{O}-\mathrm{H}$ stretching mode of the hydroxyl amine group. The $\mathrm{C}-\mathrm{H}$ stretching vibration peak is exhibited at $2926 \mathrm{~cm}^{-1}$ and this peak is slightly shifting towards higher wavenumber for sawdust- $\mathrm{ZnO}$ and chitosan- $\mathrm{ZnO}$ composites. The functional peak is observed at $1630 \mathrm{~cm}^{-1}$ which is attributed to $\mathrm{H}-\mathrm{O}-\mathrm{H}$ bending vibration of sawdust as shown in Figure 1(a). Also, $\mathrm{C}=\mathrm{O}$ stretching vibration of polysaccharide band is observed at 1637 and $1567 \mathrm{~cm}^{-1}$ as shown in Figure 1(b). The observed functional peaks at 1636 and $1562 \mathrm{~cm}^{-1}$ wavenumber are attributed to deformation vibrations of $\mathrm{N}-\mathrm{H}$ bonds in primary amines as shown in Figure $1(\mathrm{c})$. The low intensity $\mathrm{C}-\mathrm{H}$ bond of the $\mathrm{CH}_{3}$ group is exhibited at $1480 \mathrm{~cm}^{-1}$. The bands are observed at 1194 and $1137 \mathrm{~cm}^{-1}$ corresponding to the stretching vibration of $\mathrm{C}-\mathrm{O}$ bonds in primary alcohol $[15,16]$. Along with these peaks, a new high intensity absorption band was observed at $424 \mathrm{~cm}^{-1}$ which corresponds to the $\mathrm{E}_{2}$ mode of hexagonal $\mathrm{ZnO}$ (Raman active) [17]. All the three samples show the characteristic peaks of $\mathrm{ZnO}$. This shift in the frequencies confirmed the formation of bond to natural fibers with $\mathrm{ZnO}$ in the nanocomposites.

Figure 2 shows the XRD patterns of coir- $\mathrm{ZnO}$, sawdust$\mathrm{ZnO}$, and chitosan- $\mathrm{ZnO}$ composites. The observed peaks are indexed with standard hexagonal structure (JCPDS-36-1451). The predominant peak orientation of (101) lattice plane is observed in all the $\mathrm{ZnO}$ composites as shown in Figure 2. Also, lattice planes (100), (002), (102), (110), (103), (200), (112), and (201) are observed in these $\mathrm{ZnO}$ nanocomposites. The peak intensities are slightly varied with type of natural fibers mixture in $\mathrm{ZnO}$. This has confirmed that the formation of $\mathrm{ZnO}$ compound is accelerated and different properties have been enhanced due to the novel natural fibers combination. The sharper and higher intense peak is observed for sawdust- $\mathrm{ZnO}$ composites which may be due to highly ordered sawdust- $\mathrm{ZnO}$ formations. Also other peak intensities are slightly varied with respect to the other combinations as shown in Figure 2. We have further investigated the intercrystalline nature and microstructural properties of nanocomposites. The crystallite size is calculated using

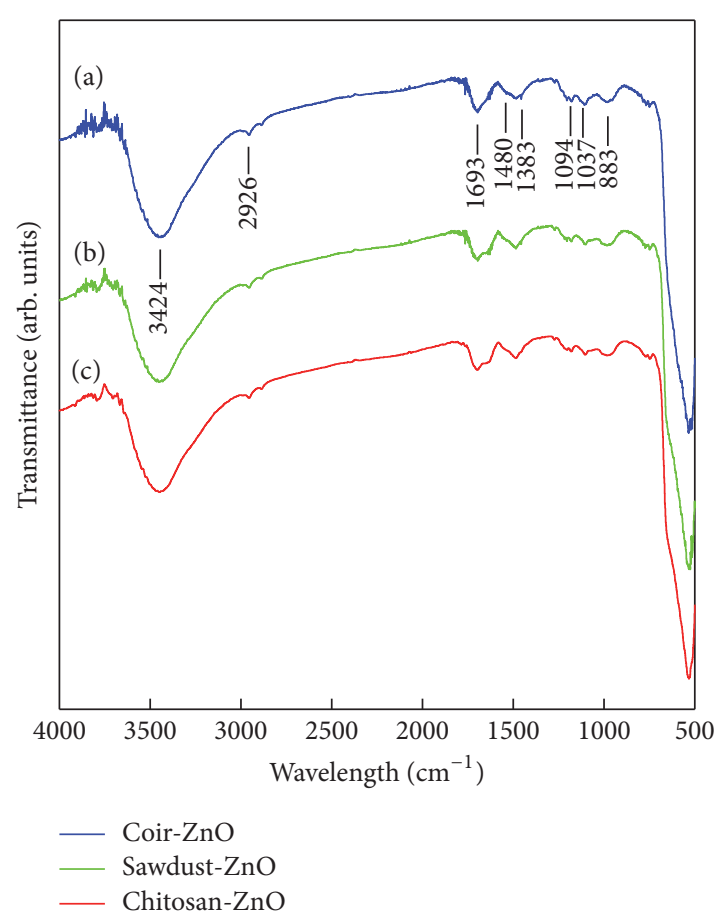

Figure 1: FTIR spectra of (a) coir-ZnO, (b) sawdust-ZnO, and (c) chitosan- $\mathrm{ZnO}$ nanocomposites.

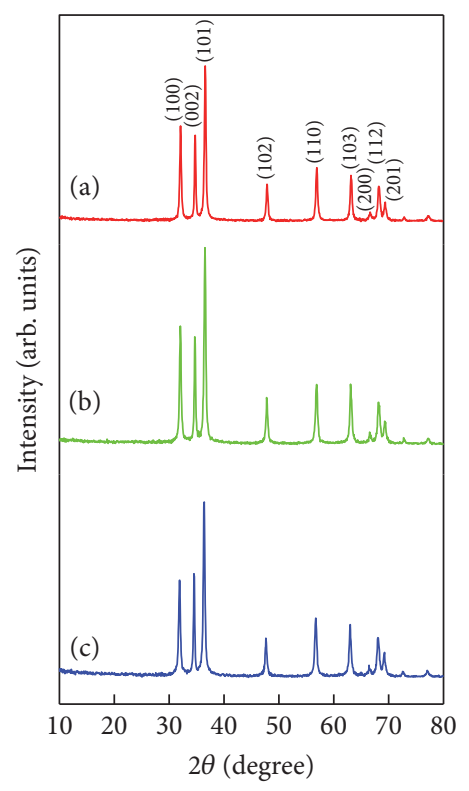

FIGURE 2: XRD patterns of (a) coir- $\mathrm{ZnO}$, (b) sawdust- $\mathrm{ZnO}$, and (c) chitosan- $\mathrm{ZnO}$ nanocomposites.

Debye-Scherer's formula to find out the microstructural characteristics [18]. The crystallite size is estimated at $19 \mathrm{~nm}$ for coir-ZnO nanocomposites. The crystallite size is increased with respect to the natural fibers as shown in Figure 3. The crystallite size value is increased to $28 \mathrm{~nm}$ for sawdust- $\mathrm{ZnO}$ and $23 \mathrm{~nm}$ for chitosan- $\mathrm{ZnO}$ samples. This may be due to 


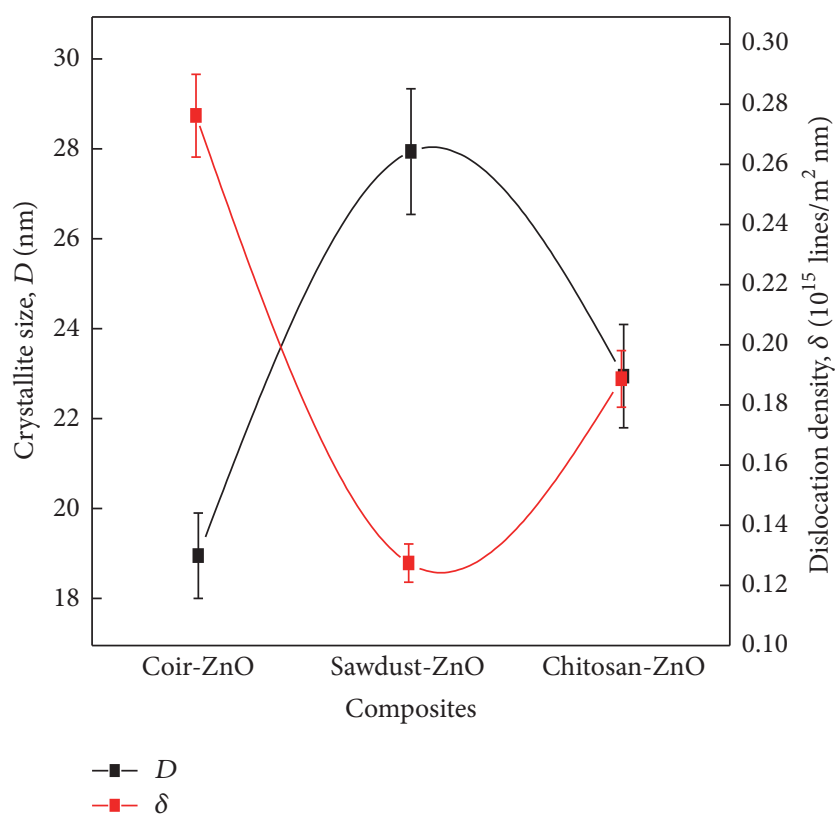

Figure 3: Crystallite size and dislocation density variations for different $\mathrm{ZnO}$ composites.

XRD peak width and intensity variations. The calculated crystallite size values are provided in Table 1 . The microstructural properties were estimated using relations (1) and (2) for $\mathrm{ZnO}$ based nanocomposites [19]. The microstrain $(\varepsilon)$ values were calculated using

$$
\beta=\left(\frac{\lambda}{D \cos \theta}-\varepsilon \tan \theta\right)
$$

and their dislocation density $(\delta)$ values were estimated using the following relation:

$$
\delta=\frac{15 \varepsilon}{a D}
$$

where " $\varepsilon$ " is microstrain, " $\delta$ " is dislocation density, " $a$ " is lattice constant, " $D$ " is crystallite size, " $\beta$ " is FWHM, and " $\lambda$ ” is wavelength of $\mathrm{X}$-ray radiation. The estimated microstrain values are at $4.50 \times 10^{-3}, 2.48 \times 10^{-3}$, and $3.32 \times 10^{-3}$ for coir- $\mathrm{ZnO}$, sawdust- $\mathrm{ZnO}$, and chitosan- $\mathrm{ZnO}$ nanocomposites, respectively, and are tabulated in Table 1 . The dislocation density variations with respect to nanocomposites are shown in Figure 3. The dislocation density values are indirectly proportional to the crystallite size values. The minimum value of dislocation density value is exhibited for sawdust- $\mathrm{ZnO}$ nanocomposites. The observed dislocation density values are $2.80,1.25$, and $1.91 \times 10^{15}$ lines $/ \mathrm{m}^{2}$ for coir- $\mathrm{ZnO}$, sawdust$\mathrm{ZnO}$, and chitosan- $\mathrm{ZnO}$ nanocomposites, respectively. The dislocation density represented the lattice misfit and strain of the composites.

The texture coefficient $(T)$ was calculated using the following expression:

$$
T=\frac{I(h, k, l)}{I_{0}(h, k, l)}\left[\frac{1}{n} \sum \frac{I(h, k, l)}{I_{0}(h, k, l)}\right]^{-1},
$$

TABLE 1: Microstructural parameters of different $\mathrm{ZnO}$ based composites.

\begin{tabular}{lccc}
\hline $\begin{array}{l}\text { Type of } \\
\text { composites }\end{array}$ & $\begin{array}{c}\text { Crystallite } \\
\text { size }(\mathrm{nm})\end{array}$ & $\begin{array}{c}\text { Microstrain } \\
\left(10^{-3}\right)\end{array}$ & $\begin{array}{c}\text { Dislocation density } \\
\left(10^{15} \text { lines } / \mathrm{m}^{2}\right)\end{array}$ \\
\hline Coir-ZnO & 19 & 4.50 & 2.72 \\
Sawdust-ZnO & 28 & 2.48 & 1.27 \\
Chitosan- & 23 & 3.32 & 1.89 \\
ZnO & & & \\
\hline
\end{tabular}

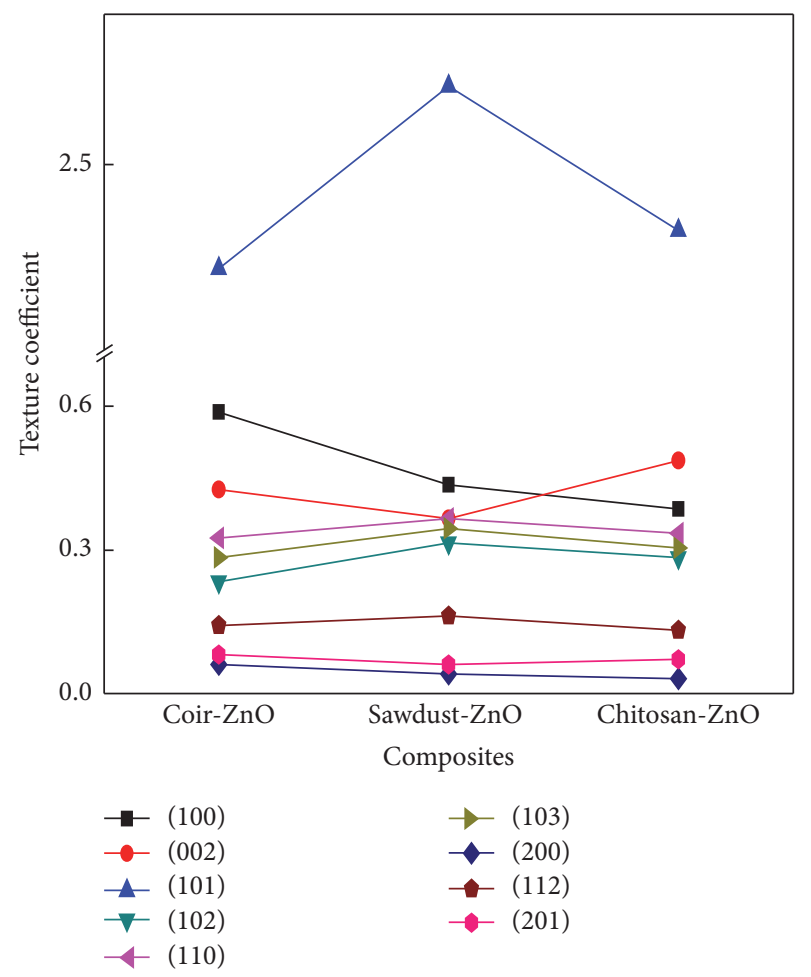

FIGURE 4: Texture coefficients variations of different $\mathrm{ZnO}$ composites.

where $I_{0}$ represents the standard intensity, $I$ is the observed intensity of $(h, k, l)$ plane, and $n$ is the reflection number. The texture coefficient of different lattice planes of $\mathrm{ZnO}$ based composites is shown in Figure 4. The predominant plane orientation of the film has high texture coefficient value. The variation of texture coefficient of coir- $\mathrm{ZnO}$, sawdust$\mathrm{ZnO}$, and chitosan- $\mathrm{ZnO}$ nanocomposites along with various crystallographic planes such as (100), (002), (101), (102), (110), (103), (200), (112), and (201) is shown in Figure 4. The texture coefficient is found to be higher for the predominant plane (101) than for other planes such as (100) and (002). Also, the texture coefficient along (101) plane is found to be slightly varied with natural fibers combinations. The texture coefficient higher than 1 indicates preferential orientation and also indicates the abundance of grains in a given $(h, k, l)$ direction. From the estimated texture coefficients, the highly textured crystalline nature is exhibited for sawdust- $\mathrm{ZnO}$ nanocomposites. 


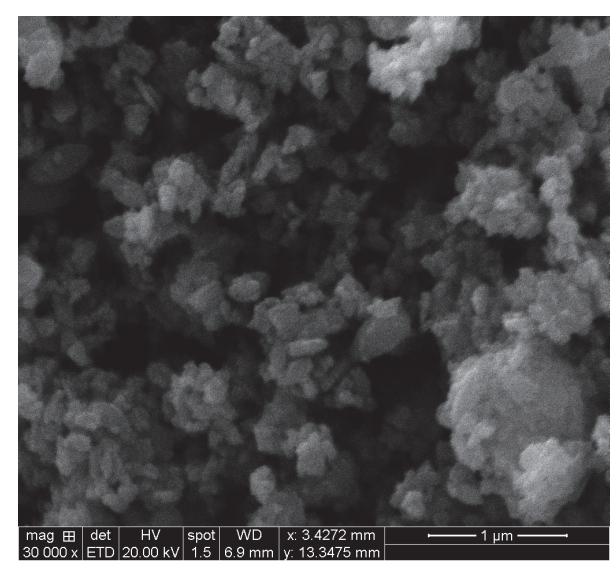

(a)

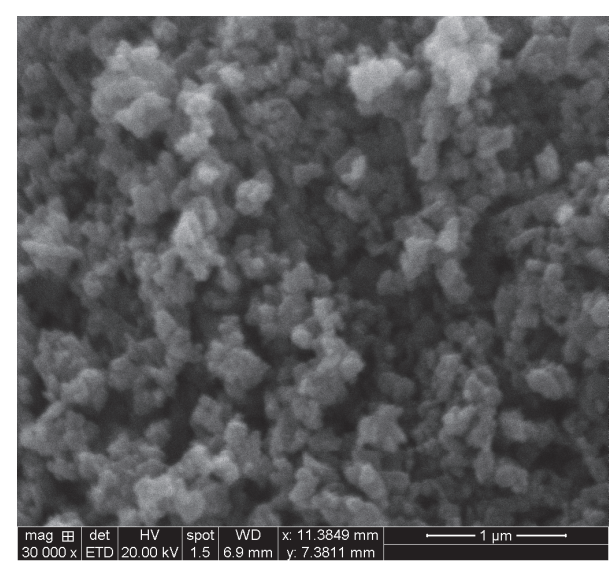

(b)

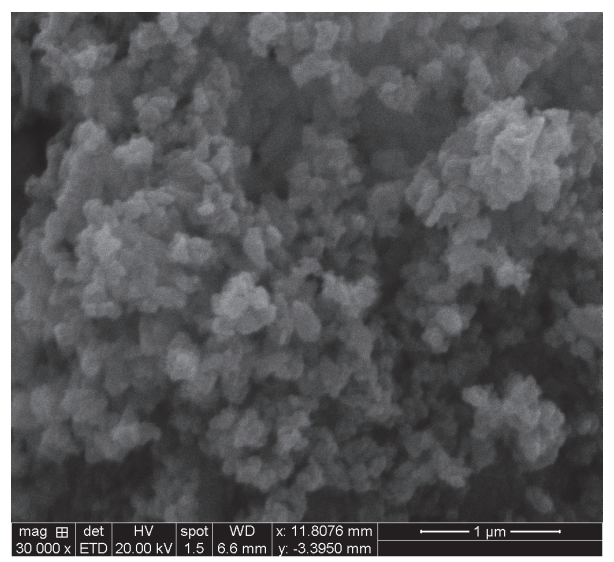

(c)

Figure 5: SEM micrographs of nanocomposites: (a) coir- $\mathrm{ZnO}$, (b) sawdust- $\mathrm{ZnO}$, and (c) chitosan- $\mathrm{ZnO}$.

The surface morphology and size distribution of coir$\mathrm{ZnO}$, sawdust- $\mathrm{ZnO}$, and chitosan- $\mathrm{ZnO}$ nanocomposites are shown in Figures 5(a)-5(c), respectively. The irregular rodlike morphology has been observed in coir- $\mathrm{ZnO}$ nanocomposites and also some places; agglomeration is exhibited in Figure 5(a). Some voids and hillocks are observed in coir- $\mathrm{ZnO}$ composites. The uneven fine grains distribution is observed in sawdust- $\mathrm{ZnO}$ nanocomposites (Figure 5(b)). The sizes of the grains are observed at $\sim 150-200 \mathrm{~nm}$. The smaller grains are linked together and formed larger grains in chitosan-ZnO nanocomposites (SEM micrograph) as shown in Figure 5(c). Moreover larger grains can improve microstructural properties of chitosan- $\mathrm{ZnO}$ composites. Also some irregular morphology is observed at the corner of the micrograph.

The size of the grains for coir- $\mathrm{ZnO}$, sawdust- $\mathrm{ZnO}$, and chitosan-ZnO nanocomposites are analysed by TEM as shown in Figure 6. From Figure 6(a), the irregular rodlike structures of particles are agglomerated in coir- $\mathrm{ZnO}$ nanocomposites. These results clearly indicated that the composites are exhibited in nanosize. The samples of sawdust$\mathrm{ZnO}$ and chitosan- $\mathrm{ZnO}$ nanocomposites (Figures 6(b) and $6(c))$ show the obvious boundary of rod- and cube-like structures, which appeared in the range of nanometer scale.
This is in good agreement with the calculated crystallite size of nanoparticles using Debye-Scherer formula.

The study of UV-Vis absorption is an important tool for the evaluation of the changes in the prepared semiconductor materials. The absorption first decreases rapidly in ultraviolet region and then in the visible region it has saturated linearly with small slope. The absorption as function wavelength for coir- $\mathrm{ZnO}$, sawdust- $\mathrm{ZnO}$, and chitosan- $\mathrm{ZnO}$ nanocomposites is shown in Figure 7. The absorption peaks are observed at $281,295,301,322$, and $334 \mathrm{~nm}$ in UV region. The observed absorption peak of 281 and $301 \mathrm{~nm}$ is corresponding to the coir- $\mathrm{ZnO}$ and chitosan- $\mathrm{ZnO}$ composites as shown in Figure 7 ( $\mathrm{a}$ and b). Also 295, 322, and $334 \mathrm{~nm}$ position peaks are related to chitosan- $\mathrm{ZnO}$ (Figure $7(\mathrm{c})$ ). The presence of zinc oxide in composites is represented and the peak position is lower than that of the macrocrystalline $\mathrm{ZnO}$ absorption of $372 \mathrm{~nm}$ [20]. This blue shift in the excitation absorption clearly indicates the quantum confinement property of $\mathrm{ZnO}$ nanocomposites [21]. The band gap energy $(\mathrm{eV})$ of the nanocomposites was determined by substituting the value of the absorption peak at a given wavelength in the following equation:

$$
\alpha h v=A\left(h v-E_{g}\right)^{n} .
$$




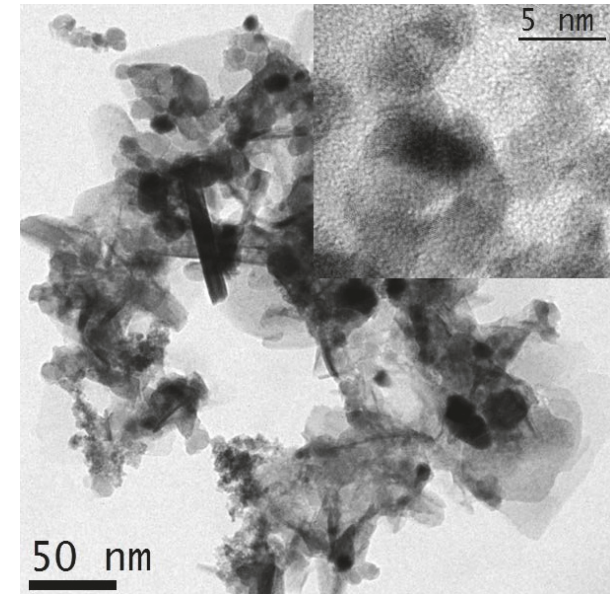

(a)

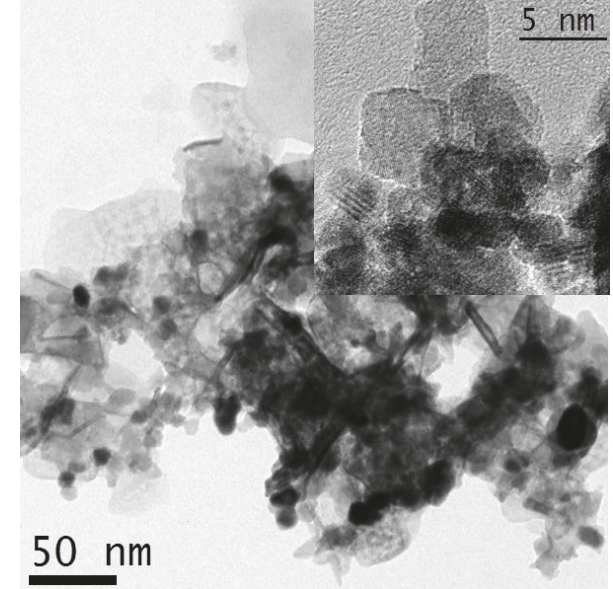

(b)

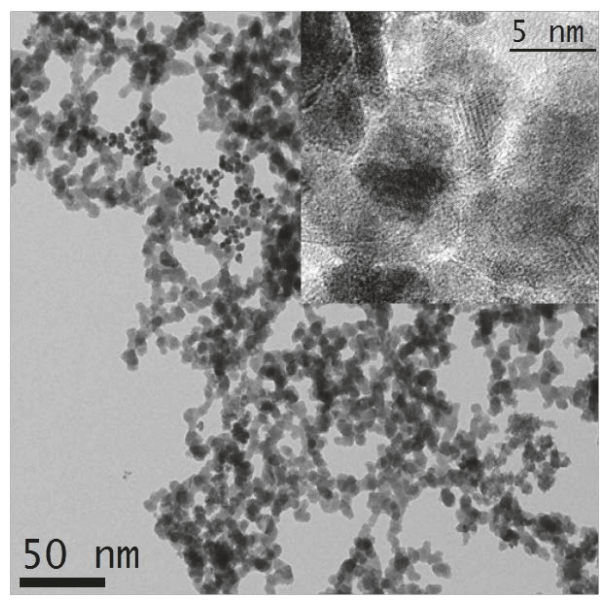

(c)

Figure 6: TEM images of nanocomposites: (a) coir- $\mathrm{ZnO}$, (b) sawdust- $\mathrm{ZnO}$, and (c) chitosan- $\mathrm{ZnO}$.

The optical band gap of coir- $\mathrm{ZnO}$, sawdust-ZnO, and chitosan- $\mathrm{ZnO}$ nanocomposites was estimated using optical absorption data derived from optical measurements. The band values are obtained by extrapolating the linear portions of the plots $(h v)$ versus $(\alpha h \nu)^{2}$ to the energy axis. It is observed that the prepared $\mathrm{ZnO}$ based nanocomposites exhibit direct transition. The optical band gap variations with respect to the nanocomposites are shown in Figure 8. The band gap values are estimated to be varying between $3.18 \mathrm{eV}$ and $3.26 \mathrm{eV}$ and it is also observed that band gaps are found to increase with combination of fibers.

Room temperature photoluminescence (PL) spectra were recorded to study the emission characteristic of prepared coir- $\mathrm{ZnO}$, sawdust- $\mathrm{ZnO}$, and chitosan- $\mathrm{ZnO}$ nanocomposites (Figure 9) [22]. From the spectra, $\mathrm{ZnO}$ has a strong UV emission band at $388-391 \mathrm{~nm}(3.25 \mathrm{eV})$ and a very weak green emission band at $461-463 \mathrm{~nm}(2.67 \mathrm{eV})$, which was attributed to the recombination of free excitations through an excitonexciton process [23]. The visible light (VL) luminescence band in the range $450-700 \mathrm{~nm}$ is related to defects and oxygen

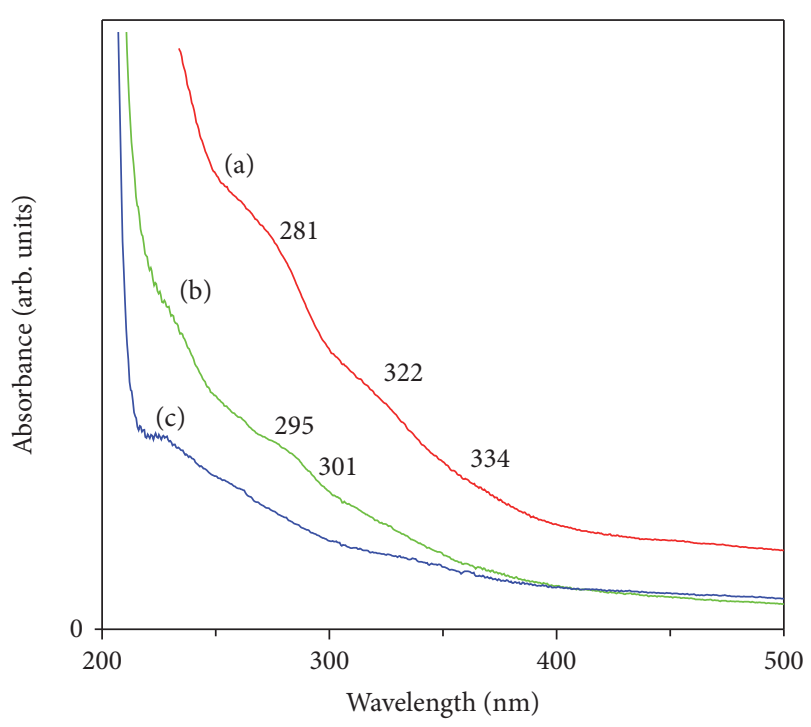

FIGURE 7: Absorbance spectra variations of (a) coir- $\mathrm{ZnO}$, (b) sawdust- $\mathrm{ZnO}$, and (c) chitosan- $\mathrm{ZnO}$ nanocomposites. 


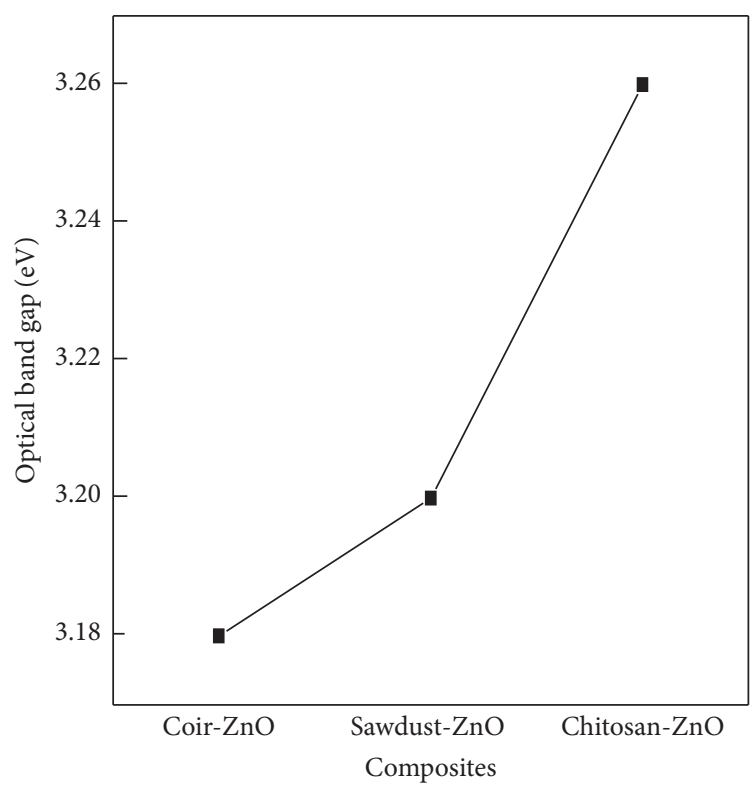

FIGURE 8: Optical band gap variations spectra of $\mathrm{ZnO}$ based nanocomposites.

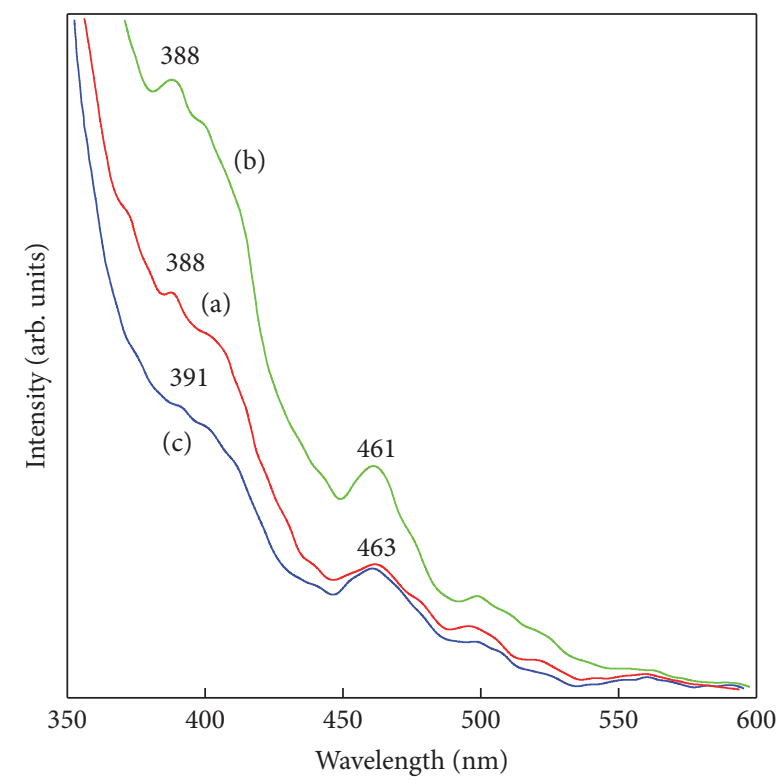

Figure 9: PL spectra of (a) coir- $\mathrm{ZnO}$, (b) sawdust- $\mathrm{ZnO}$, and (c) chitosan- $\mathrm{ZnO}$ nanocomposites.

vacancies in nanomaterials [24]. The PL spectra of $\mathrm{ZnO}$ nanoparticles, excited by a UV laser at room temperature, usually have two emission bands. One is in the UV region, which is attributed to the near-band-edge emission through excitonexciton collision processes. The other is in the visible region and presumably comes from the electron-hole recombination at a deep level (DL) emission in the band gap caused by intrinsic point defects and surface defects, for example, oxygen vacancies, zinc interstitials, and the incorporation of hydroxyl groups in the crystal lattice during solution growth [25].
There are several proposed mechanisms for the DL emission of $\mathrm{ZnO}$. Though the oxygen vacancies happen in three different charge states, the neutral, the singly ionized, and the doubly ionized states, the singly ionized oxygen vacancies (VO p) are responsible for the green luminescence in the $\mathrm{ZnO}$. In our proposed mechanism for the PL enhancement, the existence of natural fibers plays a very significant role. One would expect that, in the variations of natural fibers, the electron recombination can be easily accessed due to the band alignment as shown in Figure 9. The luminescence properties have been suppressed compared with pure $\mathrm{ZnO}$ which is due to the natural fibers presence [26]. It is interesting that the band gap emission is quenched with the natural fibers, which is in good agreement with our prediction. Thus, it is fair to conclude that the detraction of the band gap emission in $\mathrm{ZnO}$ nanocomposites is dominated by the natural fibers. The origin of the violet emission at $\sim 424 \mathrm{~nm}$ and $487 \mathrm{~nm}$ could be ascribed due to the transition occurring from $\mathrm{Zn}$ interstitials $\left(\mathrm{Zn}_{\mathrm{i}}\right)$ to the valence band, and the peak of $424 \mathrm{~nm}$ may be the result of the singly ionized oxygen vacancy (Vo) $[27,28]$. Therefore, the PL peaks of the nanocomposites were observed close to $\mathrm{ZnO}$. Typical PL spectrum of nanostructured $\mathrm{ZnO}$ has been previously reported [29]. Earlier, Lin [30] et al. have reported a strong UV emission peak at $487 \mathrm{~nm}(2.54 \mathrm{eV})$. A very small shoulder occurs at $\sim 361 \mathrm{~nm}(3.43 \mathrm{eV})$ due to bandedge transition of the $\mathrm{ZnO}$ nanocrystals [30,31]. Hence, the band gap energy of the nanocomposites is slightly shifted and it could be attributed to the existence of fiber combination of the nanocomposites.

\section{Conclusions}

With the comparison of earlier preparation methods, we have presented ecofriendly, nontoxic, abundant availability and reliable way of synthesis of $\mathrm{ZnO}$ nanocomposites. The prepared nanocomposites functional and structural properties were studied by FTIR and XRD analysis. The microstructural parameters and texture coefficients of the $\mathrm{ZnO}$ nanocomposites were measured. Morphological properties and sizes of the grains were explored by SEM and TEM studies. The optical band gap of the nanocomposites was estimated and presented in detail. The blue shift absorption was observed in the UV-spectra and also PL spectra represented the excellent luminescent properties in UV and visible region, which is expected to be a promising material for future UV emission applications. Our approach is believed to be applicable to many other semiconductor materials for the ecofriendly route preparation of metal oxide nanocomposites with novel properties.

\section{Conflicts of Interest}

The authors declare that they have no conflicts of interest.

\section{Acknowledgments}

This work was supported by the Ministry of Trade, Industry and Energy (MOTIE, 10051565) and Korea Display Research 
Corporation (KDRC) support program for the development of future devices technology for display industry. This work was also supported by the GRRC program of Gyeonggi province [GRRC AJOU 2016B03, Photonics-Medical Convergence Technology Research Center].

\section{References}

[1] I.-S. Jeong, J. H. Kim, and S. Im, "Ultraviolet-enhanced photodiode employing n-ZnO/p-Si structure," Applied Physics Letters, vol. 83, no. 14, pp. 2946-2948, 2003.

[2] C. K. N. Peh, L. Ke, and G. W. Ho, "Modification of $\mathrm{ZnO}$ nanorods through $\mathrm{Au}$ nanoparticles surface coating for dyesensitized solar cells applications," Materials Letters, vol. 64, no. 12, pp. 1372-1375, 2010.

[3] Y. Zong, Y. Cao, D. Jia, S. Bao, and Y. Lu, "Facile synthesis of $\mathrm{Ag} / \mathrm{ZnO}$ nanorods using $\mathrm{Ag} / \mathrm{C}$ cables as templates and their gassensing properties," Materials Letters, vol. 64, no. 3, pp. 243-245, 2010.

[4] M. Ju, Q. Li, and E. Wang, "Facile template-free fabrication of olive-like $\mathrm{ZnO}$ nanoparticles and their photoluminescence properties," Materials Letters, vol. 65, no. 3, pp. 507-509, 2011.

[5] C. Schaschke and J.-L. Audic, "Editorial: biodegradable materials," International Journal of Molecular Sciences, vol. 15, no. 11, pp. 21468-21475, 2014.

[6] S. Reynolds, "Preliminary studies in Western Samoa using various parts of the coconut palm (Cocos nucifera L.) as growing media," I Symposium on Artificial Media in Horticulture, vol. 37, no. 9, pp. 1983-1991, 1973.

[7] S. Anandhavelu and S. Thambidurai, "Preparation of chitosanzinc oxide complex during chitin deacetylation," Carbohydrate Polymers, vol. 83, no. 4, pp. 1565-1569, 2011.

[8] H. Zhu, R. Jiang, L. Xiao et al., "Photocatalytic decolorization and degradation of Congo Red on innovative crosslinked chitosan/nano-CdS composite catalyst under visible light irradiation," Journal of Hazardous Materials, vol. 169, no. 1, pp. 933940, 2009.

[9] R. A. Muzzarelli, Natural Chelating Polymers; Alginic Acid, Chitin and Chitosan, Pergamon Press, Oxford, UK, 1973.

[10] G. A. F. Roberts, Structure of Chitin and Chitosan, Chitin Chemistry, Macmillan Education, London, UK, 1992.

[11] M. Malini, M. Thirumavalavan, W.-Y. Yang, J.-F. Lee, and G. Annadurai, "A versatile chitosan/ZnO nanocomposite with enhanced antimicrobial properties," International Journal of Biological Macromolecules, vol. 80, pp. 121-129, 2015.

[12] M. M. AbdElhady, "Preparation and characterization of chitosan/zinc oxide nanoparticles for imparting antimicrobial and UV protection to cotton fabric," International Journal of Carbohydrate Chemistry, vol. 2012, Article ID 840591, 6 pages, 2012.

[13] A. M. Díez-Pascual and A. L. Díez-Vicente, "Poly(3-hydroxybutyrate)/ZnO bionanocomposites with improved mechanical, barrier and antibacterial properties," International Journal of Molecular Sciences, vol. 15, no. 6, pp. 10950-10973, 2014.

[14] S. Azizi, M. B. Ahmad, N. A. Ibrahim, M. Z. Hussein, and F. Namvar, "Cellulose nanocrystals/ZnO as a bifunctional reinforcing nanocomposite for poly(vinyl alcohol)/chitosan blend films: fabrication, characterization and properties," International Journal of Molecular Sciences, vol. 15, no. 6, pp. 1104011053, 2014.
[15] K. Fytianos, E. Voudrias, and E. Kokkalis, "Sorption-desorption behaviour of 2,4-dichlorophenol by marine sediments," Chemosphere, vol. 40, no. 1, pp. 3-6, 2000.

[16] R. A. A. Muzzarelli, G. Barontini, and R. Rochetti, "Isolation of lysozyme on chitosan," Biotechnology and Bioengineering, vol. 20, no. 1, pp. 87-94, 1978.

[17] M. Haase, H. Weller, and A. Henglein, "Photochemistry and radiation chemistry of colloidal semiconductors. 23. Electron storage on zinc oxide particles and size quantization," Journal of Physical Chemistry, vol. 92, no. 2, pp. 482-487, 1988.

[18] K. Sundaram, V. Dhanasekaran, and T. Mahalingam, "Structural and magnetic properties of high magnetic moment electroplated CoNiFe thin films," Ionics, vol. 17, no. 9, pp. 835-842, 2011.

[19] V. Dhanasekaran and T. Mahalingam, "Physical properties evaluation of various substrates coated cupric oxide thin films by dip method," Journal of Alloys and Compounds, vol. 539, pp. 50-56, 2012.

[20] Q.-H. Chen and W.-G. Zhang, "Continuous preparation of decorated nano zinc oxide organic sols with intense luminescence," Journal of Non-Crystalline Solids, vol. 353, no. 4, pp. 374-378, 2007.

[21] D. M. Bagnall, Y. F. Chen, Z. Zhu et al., "Optically pumped lasing of $\mathrm{ZnO}$ at room temperature," Applied Physics Letters, vol. 70, no. 17, pp. 2230-2232, 1997.

[22] P. Singh, A. Kumar, Deepak, and D. Kaur, "Growth and characterization of $\mathrm{ZnO}$ nanocrystalline thin films and nanopowder via low-cost ultrasonic spray pyrolysis," Journal of Crystal Growth, vol. 306, no. 2, pp. 303-310, 2007.

[23] K. Vanheusden, W. L. Warren, C. H. Seager, D. R. Tallant, J. A. Voigt, and B. E. Gnade, "Mechanisms behind green photoluminescence in $\mathrm{ZnO}$ phosphor powders," Journal of Applied Physics, vol. 79, no. 10, pp. 7983-7990, 1996.

[24] N. Y. Garces, L. Wang, L. Bai, N. C. Giles, L. E. Halliburton, and G. Cantwell, "Role of copper in the green luminescence from ZnO crystals," Applied Physics Letters, vol. 81, no. 4, pp. 622-624, 2002.

[25] S. Xu and Z. L. Wang, "One-dimensional ZnO nanostructures: solution growth and functional properties," Nano Research, vol. 4, no. 11, pp. 1013-1098, 2011.

[26] P. K. Samanta and P. R. Chaudhuri, "Growth and optical properties of chemically grown $\mathrm{ZnO}$ nanobelts," Science of Advanced Materials, vol. 3, no. 1, pp. 107-112, 2011.

[27] P. Xu, Y. Sun, C. Shi, F. Xu, and H. Pan, "The electronic structure and spectral properties of $\mathrm{ZnO}$ and its defects," Nuclear Instruments and Methods in Physics Research Section B: Beam Interactions with Materials and Atoms, vol. 199, pp. 286-290, 2003.

[28] Z. Fang, Y. Wang, D. Xu, Y. Tan, and X. Liu, "Blue luminescent center in $\mathrm{ZnO}$ films deposited on silicon substrates," Optical Materials, vol. 26, no. 3, pp. 239-242, 2004.

[29] E. Mosquera, J. Bernal, M. Morel, and R. A. Zarate, "Structural and optical studies of zinc oxide nanowires grown directly on zinc foil substrate by thermal evaporation method," Journal of Nanoengineering and Nanomanufacturing, vol. 2, no. 3, pp. 253258, 2012.

[30] B. Lin, Z. Fu, and Y. Jia, "Green luminescent center in undoped zinc oxide films deposited on silicon substrates," Applied Physics Letters, vol. 79, no. 7, pp. 943-945, 2001.

[31] A. S. Lanje, R. S. Ningthoujam, S. J. Sharma, and R. B. Pode, "Luminescence and electrical resistivity properties of cadmium oxide nanoparticles," Indian Journal of Pure and Applied Physics, vol. 49, no. 4, pp. 234-238, 2011. 

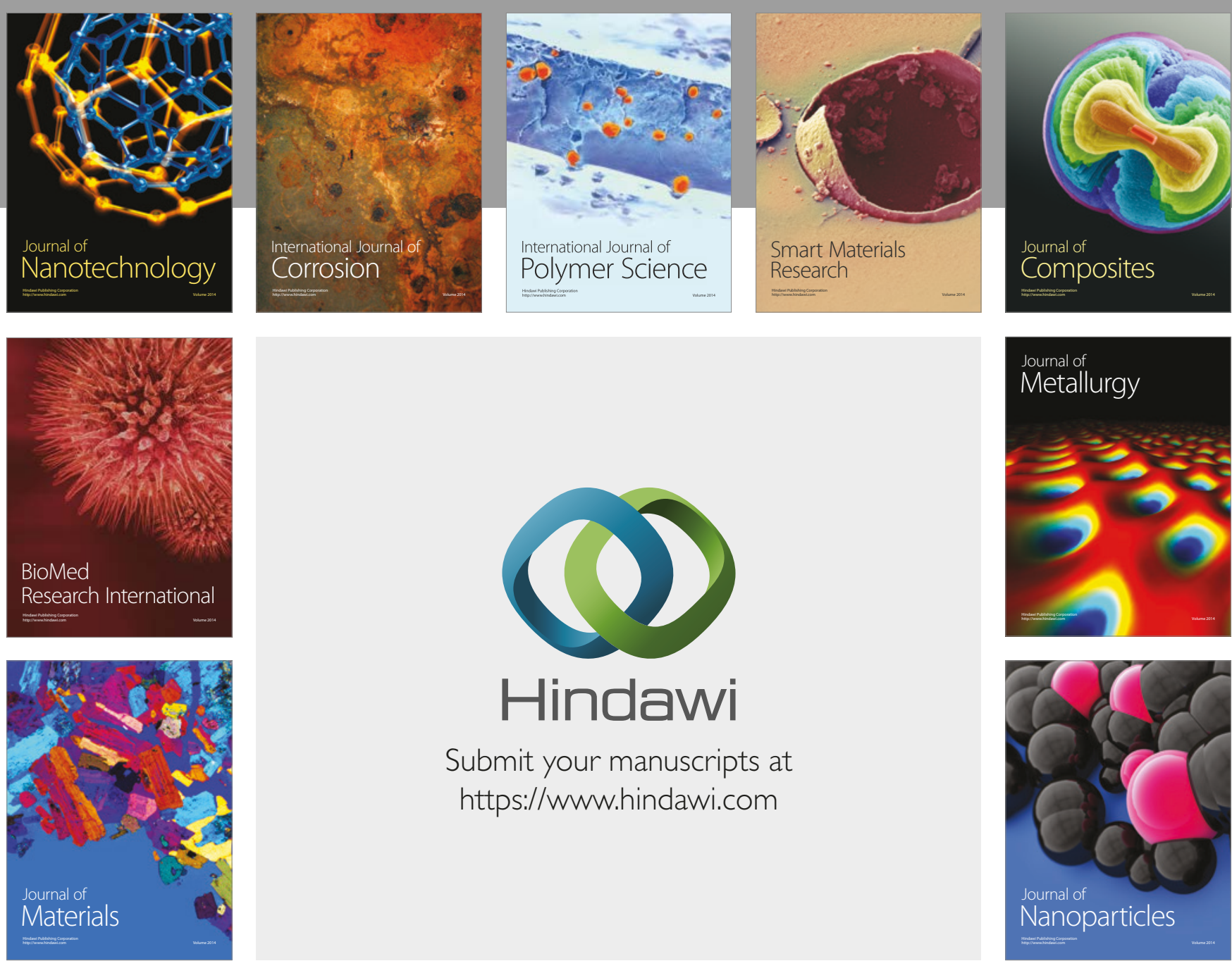

\section{Hindawi}

Submit your manuscripts at

https://www.hindawi.com
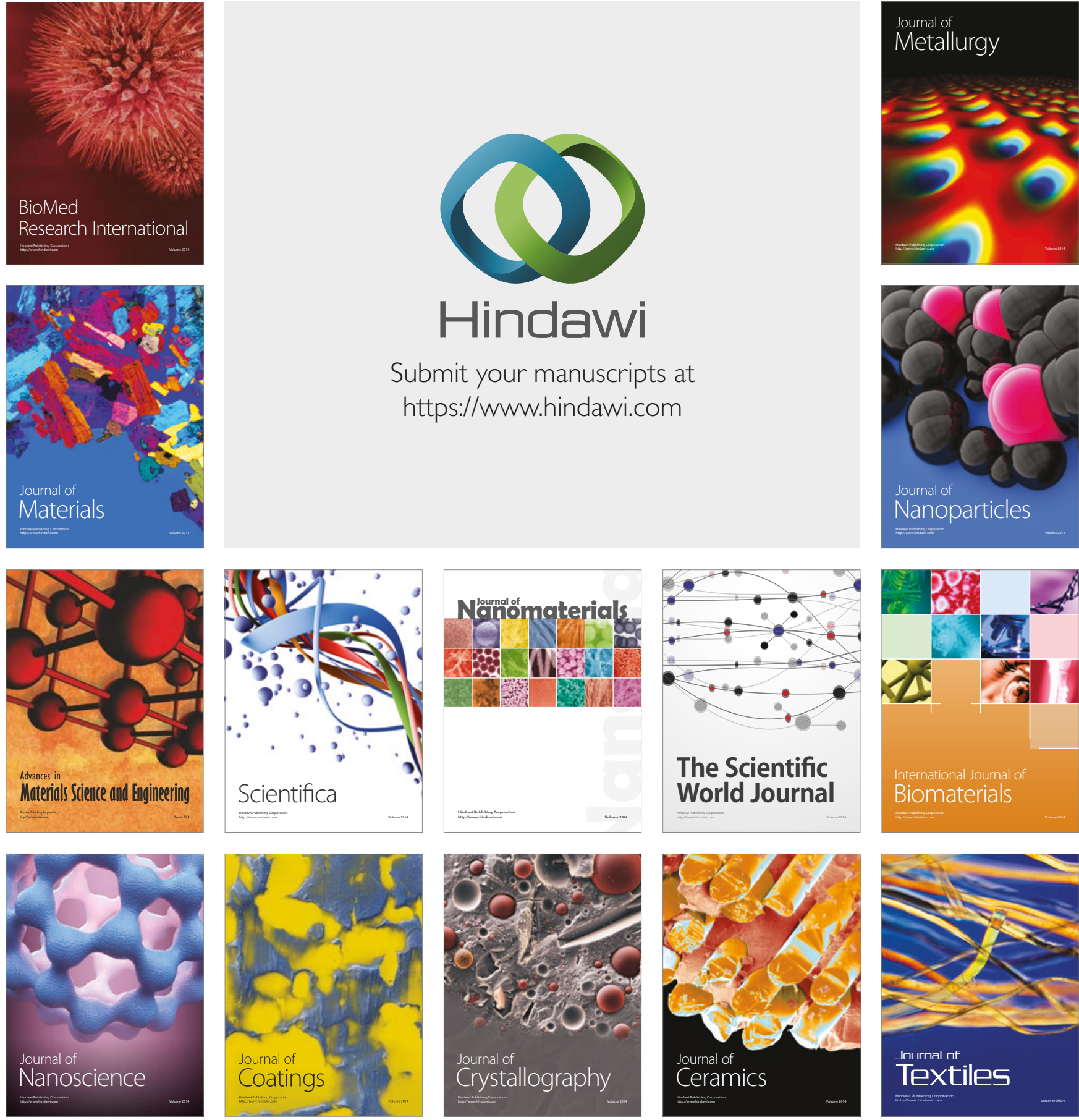

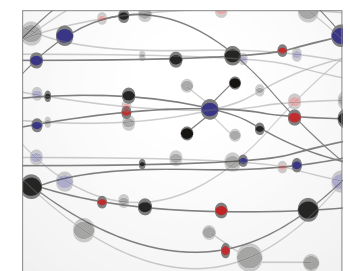

The Scientific World Journal
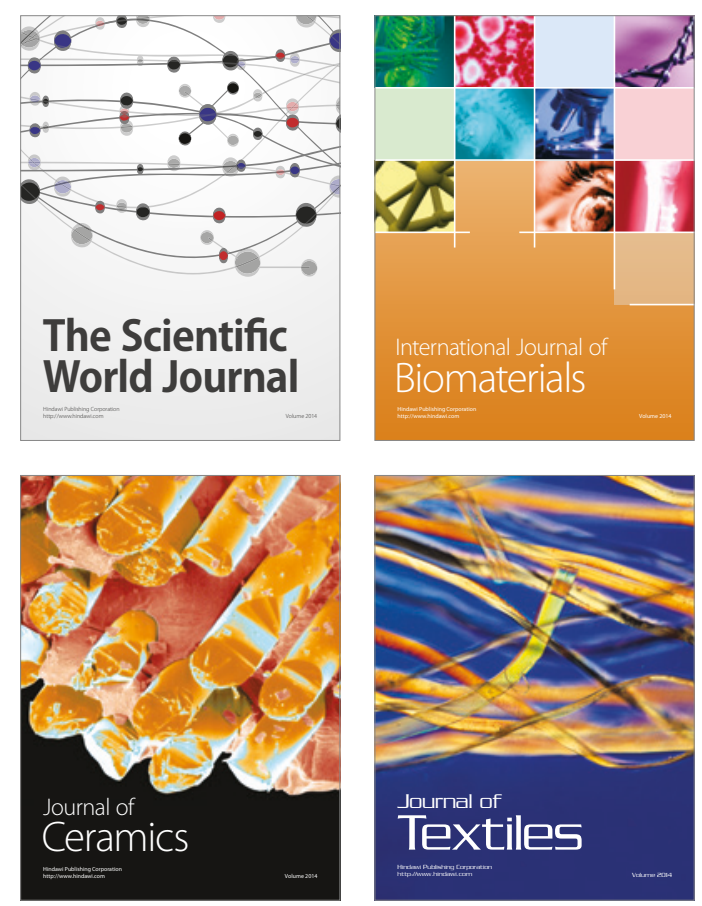